\title{
TEACHERS AS AGENTS OF SUSTAINABLE PEACE, SOCIAL COHESION AND DEVELOPMENT: THEORY, PRACTICE \& EVIDENCE
}

\author{
Mario Novelli \\ University of Sussex \\ Email:m.novelli@sussex.ac.uk
}

\section{Yusuf Sayed}

University of Sussex

Email:Y.Sayed@sussex.ac.uk

Centre for International Teacher Education (CITE)

Email: sayedy@cput.ac.za

\section{ABSTRACT}

This paper presents a 'peace with social justice' framework for analysing the role of teachers as agents of sustainable peace, social cohesion and development and applies this to research evidence from Pakistan, Uganda, Myanmar and South Africa. The paper draws on evidence from a recently completed UNICEF and ESRC funded project on education and peacebuilding, and specifically from data gathered around the role of teachers. Drawing on rich fieldwork data collected between 2014-2016 in each of the four countries, the paper will evidence the complex and contradictory role that teachers play in sustainable peace and development and its implications for teacher governance, teacher policy and teacher practice. The paper challenges the overly human capital driven logics of much teacher policy reform agendas and highlights the need and importance for a more holistic approach to teacher governance and management that recognises teachers' multiple potential to contribute to both societal peace and development.

Keywords: teachers; peacebuilding; social cohesion; social justice

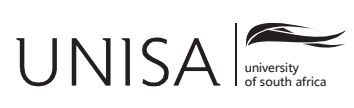

Education as Change

Volume 20 | Number 3 | 2016 | pp. 15-37

www.educationaschange.co.za
DOI: http://dx.doi.org/10.17159/1947-9417/2016/1486 Print ISSN 1682-3206 | Online 1947-9417

(C) 2016 The Author(s) 


\section{INTRODUCTION}

Teachers are a key component of any education system, and quality teaching is a prerequisite for success (Barber \& Mourshed 2007; World Bank 2012). However, teacher quality is often defined and reduced to student performance in national tests and closely linked to a human capital understanding of education's role in economic growth (Naylor \& Sayed 2014). While the economy is important, we should not underestimate both the need for and the role of education and teachers in promoting peace, building social cohesion and promoting nation-building and national identity inside and outside the classroom (Novelli 2016). This issue is particularly pertinent at a time when global inequality levels are at historic highs (Piketty 2014), and where violent conflict, wars and terrorist violence are widespread.

In the recent endorsement of the education Sustainable Development Goals, this need is recognised:

4.7 By 2030, ensure that all learners acquire the knowledge and skills needed to promote sustainable development, including, among others, through education for sustainable development and sustainable lifestyles, human rights, gender equality, promotion of a culture of peace and non-violence, global citizenship and appreciation of cultural diversity and of culture's contribution to sustainable development. ${ }^{1}$

A broader perspective on teachers' role in promoting sustainable peace, social cohesion and development often focuses on the teachers' role in such things as life skills, citizenship and peace education, moral and ethical education, child protection, human rights, skills for sustainable livelihoods, challenging gender inequalities, and practising learner-centredness (Sinclair 2002; UNESCO-IIEP 2006, 2-3). While these are important concerns, which posit that dialogue, and mutual interaction and engagement in the classroom setting is important, it should also be acknowledged that strong forms of social cohesion and peacebuilding recognise the historic and structural inequities produced and reproduced in diverse contexts. Thus, promoting social cohesion in and through teaching needs to be structural as much as psychological, recognising that education and teaching in and of itself cannot remedy all forms of inequity, particularly when they are enduring, systemic, and structural in nature and that an holistic approach needs to combine the interpersonal with the struggle to transform unjust structures. However, we should also be aware of the limits of teachers' agency to effect change, and the limits of teachers to embrace all the roles that are currently being asked of them.

This paper explores teachers' potential and limits to be active agents of peacebuilding and social cohesion in and outside the classroom context exploring how such agency is both enabled and constrained in four diverse country policy contexts: Myanmar, Pakistan, South Africa and Uganda. The paper specifically explores the governance of teachers, their training and professional development, their recruitment and deployment,

1 https://sustainabledevelopment.un.org/sdg4 
their morale, terms and conditions and their role in promoting peace, reconciliation, social cohesion and violence mitigation in each of the countries.

The paper will proceed as follows. First, we outline our analytical approach to researching teachers in conflict-affected contexts. Second, we briefly outline the methodological approach carried out in the four country case studies and provide a brief background to each case. Third, we will present a synthesis of findings from the research that explores a range of key issues: teacher agency for peacebuilding, teacher recruitment and deployment, teacher training, and teachers and the curriculum. Fourth, we will distill some key conclusions from the research on the role and potential of teachers to contribute to social cohesion and peacebuilding.

\section{THE 4 R ANALYTICAL FRAMEWORK}

This paper is underpinned by a 'peace and social justice' framework for researching education systems (Novelli, Cardozo, \& Smith 2015), which provides a distinctive focus on the role of education in promoting peace, social cohesion and sustainable development from a '4 R's perspective', linking the analytical dimensions of Redistribution, Recognition, Representation and Reconciliation.

The approach emerged out of a broader critique of the failure of both the international peacebuilding and education communities to embrace adequately and unleash education's potential to promote peacebuilding and social cohesion. The former often see education as something peripheral to the core business of peacebuilding, that can come later - after security, democracy and markets have developed; and the latter see the peacebuilding and social cohesion role of education as something subordinated to its economic and human capital role (see Novelli \& Smith 2011). In its stead, we argue for a more holistic approach to education's role, which can produce both a more sustainable peace and a more holistic education system equipped to tackle the huge social, economic, political, cultural and environmental challenges that we face.

This framework combines social justice and transitional justice thinking to develop a normative framework for the study of education and peacebuilding that recognises the multiple dimensions of inequality and injustice that often underpin contemporary conflicts and the need to address the legacies of these conflicts in and through education. The framework is rooted in broader and well-established peacebuilding thinking (Galtung 1976; Lederach 1995; 1997) on the need to address both negative peace (the cessation of violence) and positive peace (the underlying structural and symbolic violence that often underpins the outbreak of conflict). It also recognises the importance of addressing the 'legacies of conflict' in tandem with addressing the 'drivers of conflict', and the tensions between these two objectives.

Within conflict studies, there has been a long and heated debate on the relationship between inequality, injustice and violent conflict. The debate is often framed in terms of 'greed versus grievance' explanations, with the former suggesting that wars are driven 
less by justified 'grievances' and more by personal and collective 'greed' (Collier \& Hoeffler 2004). Humans are viewed as engaged in conflict as 'economic agents' making cost-benefit calculations and trying to maximise returns on engagement in violent conflict. For these thinkers, the route to peace and security is not through addressing injustice, inequality and structural exclusion, but through increasing the cost of access to resources for violent actors. A strong critique of this work argues that horizontal inequalities (between groups) are important indicators for conflict outbreak (Stewart 2010), arguments supported by strong econometric evidence (Cederman, Wiedmann \& Gleditsch 2011). Horizontal inequalities, which often relate to ethnicity, tribe, or religion, involve a range of dimensions: economic (access to land, income, and employment), political (access to political power and representation), social (access to public services), and cultural (respect for difference and identity, language rights, etc.). In armed conflicts, real or perceived horizontal inequalities can provide a catalyst for group mobilisation and uprisings. There is limited research on the relationship between education and inequality in the outbreak of armed conflict. However, recent quantitative research drawing on two international education inequality and conflict datasets (FHI 360 2015) demonstrates a robust and consistent statistical relationship, across five decades, between higher levels of inequality in educational attainment between ethnic and religious groups, and the likelihood that a country will experience violent conflict. However, this research is less able to identify causal mechanisms, or explain the complexities of understanding those. Therefore, as the authors note in their conclusions, there is a need to explore the multiple dimensions of inequality beyond just educational outcomes, as well as the different ways in which the education system might contribute to or alleviate conflict.

The 4Rs framework builds on this thinking, developing a normative approach that seeks to capture the multiple economic, cultural, political, and social dimensions of inequality in education and the ways in which these might relate to conflict and peace (see Novelli 2016; Novelli, Lopes Cardozo \& Smith 2015). The framework combines dimensions of recognition, redistribution, representation, and reconciliation, linking Fraser's $(1995 ; 2005)$ work on social justice with the peacebuilding and reconciliation work of Galtung (1976), Lederach $(1995 ; 1997)$ and others, to explore what sustainable peacebuilding might look like in post-conflict environments. The examination of inequalities within the education system seeks to capture the interconnected dimensions of the '4 Rs':

- Redistribution concerns equity and non-discrimination in education access, resources, and outcomes for different groups in society, particularly marginalised and disadvantaged groups.

- Recognition concerns respect for and affirmation of diversity and identities in education structures, processes, and content, in terms of gender, language, politics, religion, ethnicity, culture, and ability. 
- Representation concerns participation, at all levels of the education system, in governance and decision-making related to the allocation, use, and distribution of human and material resources.

- Reconciliation involves dealing with past events, injustices, and material and psychosocial effects of conflict, as well as developing relationships of trust.

The framework provides a useful tool to analyse the extent to which education might support cross-sectorial programming for conflict transformation and as an analytical tool for the education sector. In Table 1, below, we outline some of the types of 'teacher' related issues that are pertinent from this perspective for this paper's focus.

Table 1: Analysing teachers' agency through the 4 Rs

\begin{tabular}{|l|l|}
\hline & $\begin{array}{l}\text { To what extent is education supporting teacher agency for } \\
\text { peacebuilding? (potential 'indicators') }\end{array}$ \\
\hline $\begin{array}{l}\text { Redistribution } \\
\text { (addressing } \\
\text { inequalities) }\end{array}$ & $\begin{array}{l}\text { - Equitable resource distribution as well as vocational and } \\
\text { - Tevelopmental opportunities for teachers from diverse identity groups } \\
\text { - Targeted deployment and recruitment to redress inequities } \\
\text { Classroom, and the school }\end{array}$ \\
\hline $\begin{array}{l}\text { Recognition } \\
\text { (respecting } \\
\text { difference) }\end{array}$ & $\begin{array}{l}\text { - Diversification of the teaching work force } \\
\text { - Empowering teachers to recognise and respect differences } \\
\text { - Empowering teachers to communicate differences empathically and } \\
\text { conflict-sensitively }\end{array}$ \\
\hline $\begin{array}{l}\text { Representation } \\
\text { (encouraging } \\
\text { participation) }\end{array}$ & $\begin{array}{l}\text { - Ensuring opportunities of participation and representation of teachers } \\
\text { in education structures, across backgrounds and identity groups }\end{array}$ \\
\hline $\begin{array}{l}\text { Reconciliation } \\
\text { (dealing with } \\
\text { past, present and } \\
\text { future injustices) }\end{array}$ & $\begin{array}{l}\text { - Participatory school culture and administration } \\
\text { - Enabling teachers to foster active participation in the classroom }\end{array}$ \\
\hline
\end{tabular}

\section{METHODOLOGY}

This paper is part of the work of the Research Consortium on Education and Peacebuilding, which was co-led by the Universities of Amsterdam, Sussex and Ulster, and supported by UNICEF's Peacebuilding, Education and Advocacy (PBEA) programme as well as a ESRC-DFID Pathways to Poverty Alleviation Research Grant led by the University of Sussex (2014-2016). The University of Sussex led the research theme on teachers. The consortium carried out extensive fieldwork between September 2014 and July 2015 
in four countries: Myanmar, Pakistan, South Africa and Uganda in partnership with colleagues in each of the participating countries. ${ }^{2}$

The overarching aim of the teachers' study was to identify elements of education policy interventions that have enabled teachers to become active agents of peacebuilding in conflict-affected countries that may inform future interventions and vice-versa, and to identify those policies that appear to be undermining teachers' agency. The research adopted a qualitative approach, drawing on a range of data sources including one-toone interviews with diverse education and peacebuilding stakeholders in each country, focus groups with teachers and students, paper-based questionnaires for teachers, lesson observations (at teacher education institutions), analysis of existing statistical datasets, and policy documents. This approach enabled the inclusion of multiple and comparative perspectives, with hundreds of student-teachers, policy makers, facilitators/teachers/ principals participating in the study across the four countries. Throughout the research process, from conception to completion, we also engaged with a wide range of national and international stakeholders: international agencies, national government officials, INGOs, NGOs, teachers, youth and students.

\section{COUNTRY CASE STUDIES: BACKGROUND}

The four country case studies provide a high degree of contrast relating to the relationship between education and peacebuilding, in terms of geographical diversity, the nature and temporality of the conflict contexts and the drivers and root causes that underpin them. They also offer a rich terrain for understanding the capacity and commitment of different states to effect durable peace and social cohesion in and through education. South Africa emerged out of the struggle against apartheid, a conflict rooted in racism and social exclusion, whose legacies and inequalities remain more than two decades after the cessation of armed conflict. South Africa provides us with a rich resource to reflect more historically on the challenges and possibilities for the education system to contribute to promoting sustainable peacebuilding. Uganda, another country in Africa, remains divided between a peaceful South and Central region and a Northern region that has suffered a series of punctuated armed conflicts for almost three decades. Pakistan, in South Asia, is a huge country that has suffered from a series of conflicts in recent years, linked to instability in Afghanistan, the global 'war on terror', regional tensions with its neighbour India and violent internal political unrest. Finally, Myanmar presents us with a case study from South East Asia, of a country on the brink of entering a postconflict period after decades of highly authoritarian military rule, challenged by a range of armed and non-armed ethnic and political movements.

2 The full reports and further background to the research consortium are available at https://educationanddevelopment.wordpress.com/rp/research-consortium-education-andpeacebuilding/ 


\section{CROSS-CASE ANALYSIS: TEACHERS, SOCIAL COHESION AND PEACEBUILDING}

In this section we draw out some emergent issues in relation to the role of teachers as agents of social cohesion and peacebuilding and the insitutional networks within which they are embedded. Data from all four countries is retrieved from our country reports (see: Higgins et al. 2015; Durrani et al. 2015; Sayed et al. 2015; Datzberger et al. 2015). ${ }^{3}$

\section{Teacher agency and peacebuilding}

First, what is clear from the case studies is that we cannot begin to talk about teacher agency and peacebuilding without locating the discussion contextually and in relation to several context specific issues including teachers' status, morale, motivation and pay and conditions. While these conditions are not unique to conflict-affected contexts, they are often intensified in these situations due to resource constraints and weak governance systems. In all cases, but to differing degrees, teachers face a situation of declining status, where teaching as a profession is often entered into reluctantly, where attrition rates are high, where demands are ever increasing and where pay is both low and irregularly delivered, and conditions are increasingly being eroded. Ironically, this low status in some locations - Pakistan and South Africa - has led to the increased feminisation of the profession, and we should be cautious of seeing this as a positive outcome. In Uganda low morale appears linked to high attrition rates, high absenteeism and low motivation, which inevitably erode teachers' potential to be moral leaders and agents of change. Uganda's legacy of tribalism associated with nepotism also impacts on teachers' understanding of their role and agency. Even in Myanmar, where the status of the profession was higher, this has been undermined by chronic underinvestment in the education sector as a whole, despite recent salary increases. Furthermore, we should also be cautious of generalising teachers' experiences, as conditions of work, class sizes, and social challenges vary widely within countries, as evidenced clearly in the data on South Africa. In Myanmar, there are palpable differences in morale and motivation between state and non-state schools, reflecting the role of education in ethnic struggles and a more political conceptualisation of the teaching vocation in these schools. In Pakistan, there appear to be real differences in pay and conditions between the state and private sector, with serious gender inequalities within the private sector. In Uganda the private-public divide is also significant, impacting on the equitable distribution of teachers and on teacher motivation.

We can draw a number of conclusions in terms of redistribution, recognition, representation and reconciliation from the broad data. First, though the issue varies in degrees both between and within countries, inadequate redistribution of resources

3 Full country reports available at https://educationanddevelopment.wordpress.com/rp/ research-consortium-education-and-peacebuilding/ 
is central to teachers' own sense of well-being, both in terms of resources directed towards teachers themselves and the education system more generally. Issues of status and the recognition that teachers feel in society for their profession, compounded by low pay and poor conditions often further demoralise teachers and limit their potential as agents of social cohesion. While many teachers express commitment to teaching and see their work as a vocation, this becomes undermined when pay, conditions and status are eroded, particularly when teachers are marginalised from key decision-making processes and their representation is undermined. One can see from the Myanmar case that many of the teachers working in ethnic schools maintain high levels of motivation due to political commitment, but increasing demoralisation seems prevalent across cases. This undermining of teachers inevitably weakens their chances of being active agents of reconciliation and social change.

Second, what is evident is the need to locate our understanding of teachers within complex local and national histories. As such, peacebuilding interventions need to be context specific acknowledging how individuals' and groups' attitudes and values have been formed and shaped by particular conflict-ridden histories. Everything in South Africa, teachers included, remains influenced by the legacies of colonialism and apartheid, and the complexity of gender, race, ethnicity and class relations manifest themselves in multiple ways, impacting on teacher agency for social cohesion and peacebuilding. In Pakistan, an assimilationist and gendered national ideology limits teachers' capability as agents of inclusion. In Myanmar, the complex history of struggle against authoritarianism and the balance of social forces enters the classroom both in the state and non-state sectors, with very different effects. Peacebuilding and social cohesion tensions emerge from all of these challenges. Policies intended to vindicate representation and recognition issues - particularly in South Africa and Myanmar might come into tension with policies that seek to smooth over difference and build national unity. Similarly, policies of redistribution, encouraging teachers to work in remote areas, might produce resentment from local communities who see their identities threatened by the cultural and lingusitic differences that teachers coming from outside bring.

Third, national and global policy influences appear to inhibit or facilitate teacher agency in peacebuilding and social cohesion. Global discourses of quality and efficiency contrast with the need to redress inequities and promote redistribution; ideas of promoting 'meritocracy' (even if a positive attempt to redress cronyism and nepotism in the sector - as in Pakistan) appear to reinforce inequalities in the representation of minorities or under-represented groups. Even where there are serious national efforts to redress historical under-representation, these measures can be undermined locally through the political agency of actors unwilling to change and vice-versa.

Fourth, and in the context of the above complexities, there appears to have been a series of interventions in all contexts over the years to expand the role and function of teachers - from election monitors, HIV awareness transmitters, conflict mediators, and 
counsellors to social workers - that can at times be seen as over ambitious. The question must be raised as to how much we can expect a teacher to do, particularly those in the most challenging environments - which are precisely where their role as peacebuilder and agent of social cohesion is most needed.

\section{Teachers and violence}

A complex picture of teachers' relationship to physical violence emerges from the research. Across the studies we can see teachers as victims of violence at a range of levels and of a variety of types: from victims of political violence - perpetrated by state and non-state actors alike, and gender-based violence to victims of student attacks, crime and gang-based violence, and finally as victims of symbolic violence through discrimination in relation to their cultural, race, ethnic, linguistic or socio-economic backgrounds. Similarly, teachers also appear as perpetrators of violence, particularly through engagement in corporal punishment and gender-based violence on students. There is also evidence in some countries of violence and gender-based violence perpetrated by teachers on fellow teachers. Furthermore, teachers may enact symbolic violence through discrimination in relation to the cultural, race, ethnic, linguistic or socio-economic backgrounds of students. The drivers of violence are clearly mediated through widely different contexts, which themselves reflect broader societal norms and values and complex histories of violence within which teachers are located. In all contexts, discussing and reporting violence in its different forms often remains a taboo subject and lack of evidence should not fool us into thinking there is not a problem.

In Pakistan, teachers have been victims of direct violent political attacks by design or default - where education institutions and the education system is caught up centrally in the fallout from the conflict in Afghanistan and the broader 'war on terror', particularly, though not exclusively, in the Northernmost regions. In this context teachers and education institutions are often perceived as representative of an external 'Western' education system, perceived as collaborators with external powers - outposts of the state - 'threatening' particular Muslim identities. In Myanmar, particularly in the more conflict-affected regions, teachers feel vulnerable to attacks in militarised areas, and others feel threatened by the local community, fearing being seen - as in Pakistan - as civil servants and outposts of the state. In South Africa, the legacy of apartheid, where state sponsored terrorism and political violence was widespread and structural inequality inscribed in the state, appears to have had profound effects on the post-conflict environment, where arguably violence has become normalised in everyday life. In this context attacks on teachers by pupils is widespread. This type of student on teacher violence is not documented in the other case studies.

The most prevalent form of violence that emerges across the case studies is that of teacher on student violence through corporal punishment. This appears widespread and culturally accepted in most of these contexts, despite national legislation in 
several contexts to prohibit its use. In Pakistan, ambiguous state responses to corporal punishment reinforce the pervasive culture of corporal punishment in schools, leading many students to drop out of education. In Uganda Corporal punishment was banned in 2008. Nevertheless, it remains a dominant practice, with a MoESTS study in 2012 finding that 74 per cent of children in primary school and 75 per cent in secondary reported being caned (UCRNN 2014). The cases of Myanmar and South Africa suggest similar findings. This appears to be a central domain where better and more informed teacher training and professional development could assist in challenging the practice and breaking cultures of violence in schools.

Gender-based violence appears as a key issue in all contexts, and one that is underreported due to its taboo status. Evidence in both South Africa and Uganda point to a significant prevalence of teachers engaging in GBV against students and colleagues, including transactional sex for grades incidents. In South Africa, the evidence appears particularly damning, though this might reflect research focus and interest, which may not have been similar in Pakistan, Uganda and Myanmar. In recent years, South Africa refined its legal framework to address the problem, legislating dismissal for teachers who carried out GBV on colleagues or students, and banned relationships with students where teachers were employed. However, weak implementation has meant that this had little impact on the ground. Furthermore, teaching, as a feminised profession, where men in all contexts appear more prevalent in management roles, facilitates teacher on teacher GBV as some men use their positional power to pressure and coerce female colleagues.

These different and complex modes of violence all in their own ways undermine peacebuilding and social cohesion and seem to all circulate around issues of identity, status and the exercise of power to try to produce certain desired outcomes. Whether that be armed groups over teachers and students, male teachers over female teachers, teachers over students and students over teachers. The pervasive nature of violence in many of the country case studies inevitably undermines processes of sustainable peacebuilding inducing both fear and the potential for retribution and the cyclical transmission of cultures of violence from teachers to students to communities and vice versa.

\section{TEACHER GOVERNANCE}

Teacher recruitment and deployment are an important component in the relationship between education, social cohesion and peacebuilding. Questions of who has access to initial teacher training and the contents therein, the degree to which trainees and established teachers have opportunities to experience diverse environments and where they are subsequently employed, influence equality in relation to ethnic, regional, gender and socio-economic representation in the system. Once in post the distribution of teachers from different backgrounds, and their preparedness to work in a range of settings will influence the diversity experienced by the children and young people they 
teach. Therefore, it is vital to consider challenges experienced by each country in this regard. From the data on teacher governance gathered, the two key cross-cutting issues in all the four countries are related to 'equity' and 'attention to context'.

\section{Equity}

In Pakistan (see Durrani et al. 2015), both teacher recruitment and deployment in the country have historically raised issues for quality and equity due to clientelism and political intervention, partly linked to teachers' roles as election officers. As a remedy, a merit-based system was introduced, but was poorly designed to address redistribution and recognition issues, thus reinforcing gender and ethnicity imbalances. There are also issues with the representation of women, disabled and religious minorities in the teaching profession. The policy intervention only makes provision for quotas and though these may be necessary they are insufficient. Additional steps beyond the quotas would be required to facilitate the inclusion of those who are under-represented in the profession.

In South Africa (see Sayed et al. 2015) the legacy of inequalities under apartheid and an ANC government committed to redressing this has led to more equity-based policy interventions. However, results have been mixed. Between 1994 and 1999, the state undertook two main interventions to rationalise both recruitment and deployment and address the unequal remuneration between racial and gender groups. The intervention between 1994 and 1999, that aimed to rationalise both recruitment and deployment and address the unequal remuneration between racial and gender groups led to a reduction in the teaching force as teachers left the profession rather than accept redeployment and it increased budgets which had adverse effects on other inputs such as teacher/learner ratios. The Teachers Rural Incentive Scheme (TRIS) had similar objectives, and mixed results. PPNS (post provisioning norms) were introduced as a mechanism to ensue a fairer distribution of teachers in relation to both subject shortgages and geographical inequities. Chisholm (2009) contends that PPNs entrenched the relative advantage of schools favoured during apartheid because the mechanism worked to the benefit of schools that have highly qualified teachers and could recruit more. This is exacerbated by the low attractiveness of teaching, poor working conditions, low salaries, inefficient teacher recruitment and retention processes, as well as deployment systems in place at provincial and school level militating against rather than promoting equity. The Funza Lushaka Bursary Programme (FLBP) is a multi-year, service-linked bursary scheme designed to raise the number of newly qualified teachers entering schools particularly in poor and rural areas, by offering full-cost bursaries to eligible students who enrol in specific ITE programmes. There are several challenges in implementing this policy. A key conceptual challenge for the FLBP is that it acts as a compromise between an incentive for broad-based teacher training, an incentive for teachers to choose to work in rural areas and an incentive for teacher training to address skill-shortages in the economy (maths and science). As such it has been introduced to work as a general incentive to 
attract students to the teaching profession. Ensuring that graduates teach certain targeted subjects/phases/geographies has been a struggle. Whilst the strategy may be working well in terms of increasing enrolment rates and the overall shape of new graduates, this does not necessarily lead to effective absorption, retention or utilisation.

In Uganda (see Datzberger et al. 2015), as with many of the other countries, teacher shortages are acute and unevenly distributed, with the North and East most affected. A lack of targeting is a factor in imbalances found in teacher recruitment. In response to the challenges a variety of schemes have been set up to incentivise rural and remote deployment. The Hard to Reach Hard to Stay allowances have been offered to teachers in remote areas since 1997. However, as early as 2007 a World Bank review found that the strategy was not achieving these objectives. From the Ugandan case it appears local hostility to external teachers being deployed, linguistic and cultural differences, and security and suitability of conditions all mediate against success.

In Myanmar (see Higgins et al. 2015) there is a sense of inequities in resources and provision of teachers between the government, monastic, ethnic and community education systems. The policy of financial incentives does not seem to work because it does not seem to resolve the disparity in educational conditions - a combination of harsh conditions, challenging relationships with school leaders and a lack of affordable accomodation and unrealistic expectations towards teachers' multiple roles. Gender is also a factor with younger females hesitant to travel to remote schools, for reasons of personal safety or family obligations. As a result of a lack of demand, it is often the least qualified and youngest teachers who are sent to some of the most challenging environments, which might further reinforce inequities in outcomes.

\section{Attention to the context}

In addition to the issue of equity discussed above, there is a sense that the internationally driven, neoliberal-inspired efficiency agenda that drives much of the reforms in all the four countries is not responsive to the needs of the local communities and teachers. The efficiency agenda does not seem to take into account the support required by teachers in difficult working conditions. Often the competencies-based frameworks are developed with an image that is much more favourable to relatively resourced schools than the actual under-resourced school reality most teachers face in conflict-affected contexts (Higgins et al. 2015). In Pakistan, the merit based system poorly addresses redistribution and recognition issues, thus reinforcing gender, and ethnicity imbalances. In South Africa the policies do not take account of institutional cultures reinforcing racial inequities. Moreover, local communities may distrust the neoliberal view of the role of teachers embedded in current education reforms, associating them with a loss of local values, an erosion of the local conceptions of the role of teachers, thus underestimating the dedication to service amongst teachers that is strongly linked to local moral and intellectual traditions. 
As is evident, there remain serious challenges to redressing equity and taking account of local contexts. Incentives and interventions need to redress the legitimate concerns of teachers and be based on sound evidence. Similarly, reflection should be made, dependent on context, as to whether resources are better focused on ensuring local marginalised community members are encouraged to enter the profession and be located in their own regions and stay there or measures introduced to encourage diversity of teacher recruitment, deployment and retention. Training local teachers in remote communities and providing them with incentives might enhance and promote key local and regional 'recognition' issues - cultural, ethnic and linguistic, but may undermine the potential for nation-building and national 'recognition' issues. Conversely, deploying teachers to remote areas might promote national redistribution and recognition issues but undermine local communities' sense of identity and self-worth and potentially place at risk the wellbeing of teachers deployed. Each has potential pros and cons in terms of peacebuilding and social cohesion, and policy needs to be grounded in evidence, consultation and holistically developed, with no easy standardised answers.

\section{INITIAL TEACHER EDUCATION (ITE)}

ITE programmes are impacted by the diverse policy environments in the four countries. In Pakistan and Myanmar the evidence demonstrates rapidly transforming policy contexts for ITE. In Pakistan recent policy measures seek to move toward ensuring teaching as a degreed profession whilst in Myanmar the changing political conjuncture has resulted in changes to ITE to make it more responsive to the needs of diverse school sectors. In contrast, South Africa and Uganda have longer histories of ITE policy reforms. In South Africa there is an ongoing policy debate about balancing institutional autonomy, as ITE is located fully within higher education institutions, with the need for a convergence in programme offering. Not surprisingly across all country contexts, the policy discourse is about improving the quality of ITE to enhance learner attainment.

Akey tension that runs across all cases is the balance between a narrow cognitive focus on literacy and numeracy (e.g. the litnum strategy in South Africa) and a more expansive focus on ITE that includes non-cognitive aims. To put it differently, there is need for an affective turn in which the values of social cohesion and peacebuilding as articulated in the new SDG goals are embedded within ITE programmes. Different attempts are made to integrate social cohesion and peacebuilding in ITE programmes across the four country contexts. On the one hand, issues of social cohesion and peacebuilding remain implicit in that a focus on classroom pedagogy, inclusive education classroom management and child-centred pedagogy are perceived as enabling teacher agency for change as is the case in for example Pakistan and South Africa. On the other hand, explicit approaches seek to include content and pedagogies for social cohesion in ITE programmes, as is the case in for example the UNICEF led Peacebuilding Education and Advocacy primary school initiative in Uganda and the UNICEF Head Teacher Training 
in Myanmar. However, even the PBEA programme tends to emphasise generic issues such as college ethos and active teaching approaches rather than harder issues of ethnic/ group conflict. It seems that many of the explicit approaches to peacebuilding and social cohesion are often driven by international agencies with a strong focus on knowledge drawn from the discipline of psychology (e.g. psycho-social care). This is often to the exclusion of other knowledges including those that focus on historical knowledge (e.g. unpacking the histories of conflict) and sociological knowledge (e.g. addressing issues of power and inequity which are often the drivers of conflict).

Peacebuilding and social cohesion in ITE also range on a continuum from the general to the specific. Generic approaches emphasise key skills and competences in ITE such as critical-thinking skills and reflective-practitioner approaches. This is found across all ITE programmes in the four countries. For example, in Pakistan the revised $\mathrm{ADE}$ and B.Ed. curriculum is premised on the notion of the teacher as a reflective practitioner and lifelong learner. More often than not, besides the academic focus (e.g. numeracy and literacy) the donor-funded projects in Pakistan aim for inclusion in terms of gender and rural-urban equity. The curriculum does not address language of instruction, religious and sectarian differences, and the widening gap in social classes. Specific approaches are rare but include modules/topics on peacebuilding and conflict resolution and mediation skills, pedagogies of discomfort, pedagogies of hope, and social justice modules, such as in South Africa.

What is most revealing is teacher educators' and teacher education students' understandings and experiences of the ITE programmes in relation to social cohesion and peacebuilding. Their experiences are shaped by the particular historical legacies of each country. In South Africa for example, ITE programmes offer many the first opportunity to interact across racial boundaries and simultaneously they experience clustering of students and groups by racial categories. South Africa reveals interesting and noteworthy understandings of teacher education students of social cohesion and peacebuilding. For many their understandings reflect a view of peacebuilding and social cohesion as personal and inter and intra psychologically focused on notions of respect and trust. Rarely are ideas of social justice, inequality and social activism embedded in their understanding.

ITE programmes offer student teachers the opportunity to practise their pedagogic craft in the classroom through the teaching practicum. Across the case studies capacitating teacher student agency for social cohesion and peacebuilding through this approach remains implicit and is underpinned by the assumption that in managing classrooms and teaching, a student teacher will engage and deal with diversity, trauma and conflict. In rare cases, as in South Africa, explicit efforts are made to ensure that the teaching practicum can become an important means for social cohesion and peacebuilding. Noteworthy is the cross-over practicum in South Africa whereby student teachers are deliberately placed in schools that straddle racial boundaries and reflect different social- 
economic statuses. In this way a student teacher experiences what it means to teach in different schools that reflect the historical legacy of conflict.

An abiding feature of the four country case studies is that student teachers often find it difficult to translate and transfer their learning from ITE programmes into school contexts upon their appointment as teachers. For example, in Pakistan the revised curriculum of education course entitled 'Methods of Teaching' (HEC 2010, 40) for the Associate Degree in Education (ADE) provides methods of teaching that are very general in terms (e.g. inquiry method, demonstration method, activity and cooperative learning methods [2010, 42]), and the readings mainly draw on Euro-Western sources that may not necessarily have issues of language of instruction to the extent that they are prevalent in the schools in Pakistan. Also, the revised curriculum of teacher education does not take an explicit note of approaches to teaching and learning in multilingual classrooms. Likewise, in Myanmar limited attention to practical challenges faced by teachers, including multi-grade teaching, the teaching of languages other than Myanmar and inclusive education, emerged as key local issues that remained marginal in teacher education. This is not surprising but suggests that ITE programmes are but a stage in activating teacher agency for change and transformation and need to be complemented by continuing professional development.

Across the cases, there was a sense that the educators were unable to realise the full potential of ITEs to enable teachers to be agents of social cohesion. At the ITE institutions visited by the researchers in Uganda college management teams drew attention to diversity of recruitment as a positive factor, particularly in helping to bring Ugandans from different backgrounds together in the interest of national unity. Principals and senior colleagues extolled the benefits of students from different regions mixing to better understand each other, especially through extra-curricular activities. Generally, colleges also provided occasional opportunities for groups to share cultural traditions such as dance with their peers. However, college staff were less explicit as to how diversity emerges in formal class time and the extent to which groups and individuals get the chance to express regional perspectives on issues of concern. Similarly, in Pakistan findings showed that student teachers were very politically aware and held deep insightful views about social cohesion and the role of education and teachers in working towards a unified society built on justice, mutual respect and trust and held concerns on issues of poverty and social class. Yet, it appeared that the emphasis was much more on commonality than exploring the potential tensions present in diversity. Teacher educators saw these issues as peripheral to the core curriculum or brushed them aside as 'out of topic'. Notwithstanding this, there is much to be done to ensure that student teachers experience their initial teacher education as empowering so that they can become active and critical agents of social cohesion and peacebuilding. The case studies point to fostering trust, respect and belonging in and through the programmes as measures to enable this. 
Central to our concerns in this research is that the need for subject-confident highly trained teachers who can work in schools and provide students from all backgrounds with high quality subject teaching is a crucial contribution to making possible peacebuilding and social cohesion aspirations of social mobility and employability - redistribution. However, teachers trained to be committed to the promotion of representation, recognition and reconciliation - that is, to support democracy and the voices of their students, respect and value diversity and promote peace and reconciliation - are far more likely to deliver transformational learning that can build peace, social justice and social cohesion. That is to say that there does not need to be a trade off between efficiency and equity - the cognitive and the affective - and more holistic teacher training has the potential to deliver this.

The geographical location of ITEs and regionally inequitable professional support mechanisms for teachers also seem to contribute to inequities. For example, the Myanmar case study suggests that the logistics, upheaval and expense of undertaking teacher training in another area can make it difficult for aspiring teachers from ethnic and rural areas to access these institutions. As a result, the correct or incorrect association of government school teachers as belonging to the majority (Bamar, Buddhist) population is further reinforced, often leading to such teachers being perceived as outsiders in the areas to which they are deployed. Similarly, structurally, teacher education provision perpetuates the perception that conflict-affected areas are less favourably treated in Uganda, reinforcing regional disparities.

\section{TEACHERS, THE CURRICULUM AND TEXTBOOKS}

Curriculum reform is often a long and complex process. Political will appears central in promoting social cohesion, peacebuilding and reconciliation, and this is dependent on the particular configuration of social forces in each of the four country contexts.

In South Africa, when the ANC government was emerging as the governing party, there was clearly political will to remodel the curriculum, unify messages, de-racialise and detoxify the divisive political culture under apartheid through the idea of the rainbow nation. As noted by Basic Education Minister Angie Motshekga in the Curriculum and Assessment Policy Statements $\left(\mathrm{CAPS}^{4}\right)$ of 2011, these included:

- Healing divisions of the past, establishing a society based on democratic values, social justice and fundamental human rights.

- Improve quality of life and free potential of all persons.

4 http://www.education.gov.za/Portals/0/CD/National\%20Curriculum\%20Statements\%20 and $\% 20$ Vocational/CAPS $\% 20 F E T \% 20 \_\% 20 L I F E \% 20$ ORIENTATION\%20_\%20GR\%20 10-12\%20_\%20WEB_E6B3.pdf?ver=2015-01-27-154251-017 
- Lay foundations for a democratic, open society where the government is based on the will of the people and equal exercise of law.

- Build a united, democratic SA.

The national curriculum in South Africa is formulated to respond to the dual but often conflicting roles of developing human capital and fostering reconciliation in a historically divided society. This takes place alongside a policy commitment to informing students of South Africa's history, fostering caring and responsible citizenship. The present CAPS curriculum represents an attempt to make the aims of the curriculum more explicit and respond to the critical need for developing literacy, numeracy and problem-solving skills. One of its major outcomes, however, has been the devaluation of the capacity of teachers to work independently due to packed syllabi for all subjects. Another has been the transposal of the same syllabus across schools of differing socio-economic and racial composition, with little recognition of how knowledge contained in the curriculum is taken up in different contexts. While both the curriculum and textbooks reviewed for this research are not without their critics, there is a clear attempt to be more representative of the different communities, religions, and divergent histories that encompass the new South Africa.

In Myanmar, where transition from military rule remains a work in progress, political will and political divisions make progressive reform more complex. The parallel education systems each reflect the dangers of ethno-centrism in the curriculum, reflecting as they do very particular cultural histories that if transition is to be possible need to be reconciled. The research does note however some evidence of teachers on both sides of the divide mediating difficult texts in the interests of building unity and to 'swim against the current' (Metro 2015, 12 in Higgins et al 2015). In Myanmar, as with other cases (Uganda, Pakistan), innovation appears often to be coming from external agencies. With support from JICA, Myanmar's primary level basic education curriculum is being reformed in a process that started in March 2014 and is due to be completed in October 2019. The reform addresses pedagogy, content, the representation of different groups, reducing reference to the military and issues related to violence. However, in the context of ongoing military rule, curriculum developers were aware both of the need to respect ministry sensitivities while doing justice to their sense that curriculum reform should reflect national renewal and aspiration.

In Pakistan, post-9/11 curriculum reforms remain highly politically charged, with concerns with radicalisation, militancy and marginalisation amongst Pakistan youth leading donors to actively engage in this domain, whilst being countered with concerns of external interference in the internal affairs of the country, fear of cultural reform and the undermining of the centrality of the Islamic religion in the public sphere. Current curriculum reform in Pakistan, as a result, appears to have been contested by various actors. Under pressure from international actors and local civil societies curriculum reform processes resulted in the National Curriculum (NC) 2006. The NC 2006 is 
technically an improved curriculum as it takes a 'standards and benchmarks' approach to curriculum content and process that provides a focus on learning outcomes. Textbook development has been liberalised so that it is no longer the sole domain of the provincial textbook boards. However, the stringent review process ostensibly for adherence to the NC 2006 is ideologically driven and coercive in nature. National messages and implications for social inclusion are varied across subjects - English IX and X promotes cultural sensitivity and inclusion, Mathematics in NC 2006 for classes IX and X is distant and not situated in the socio-cultural environment and Pakistan studies for classes IX and $\mathrm{X}$ is assimilationist in orientation and privileges Muslims as citizens of Pakistan. In general, NC 2006 lacks adequate attention to space and voice for diverse groups, particularly women and religious minorities.

In Uganda, dimensions of social cohesion and peacebuilding in the curriculum appear to have been periodically added, often with the intervention and support from external agencies. UNESCO's influence in terms of citizenship education and UNICEF's influence in terms of peacebuilding appear evident. There is evidence in the Uganda report of more ambitious reforms underway, with the NCDC developing a studentcentered approach to promoting peacebuilding. Also, there is a greater attention to the recognition of difference related to geographical, tribal, religious, gender and linguistic diversity. The authors of the Uganda country report underline the need to teach the revised curricula ensuring that in social studies and other areas of the curriculum they have the pedagogy to engage pupils on contemporary social, cultural and political issues that impact on everyday lives; moreover, they emphasise the need to facilitate clubs, societies and activities that encourage positive social activism in the school and community and the need to put greater emphasis in the curriculum and in extracurricular activities on aspects of traditional cultures that contain a reconciliatory dimension. As with many aspects of Uganda's educational system, curriculum policy is generally sound and informed, but implementation is weak. Until the structures are in place for the effective communication of curriculum reform to colleges, schools and teachers the undoubted progress made at NCDC remains aspirational.

Debates around the History curriculum reflect the centrality of this subject across all contexts. In South Africa, critics lament an incomplete image of South African history that privileges Western history and development over the experiences of the country and the continent. There are also issues with the presentation of an ANC-dominant history of the struggle against apartheid and the emphasis on particular persons and symbols rather than a mass people's struggle. The New Generation History textbook for Grade 11 in South Africa reflects a growing interest in promoting pedagogies of critical inquiry whereby teachers explore issues of race, gender, class, xenophobia, human rights, power dynamics, genocide and their historical impact. In Myanmar, History remains highly contentious in a divided education system rooted in very different ethnic and political traditions. While some teachers' attachment to sectarian approaches to teaching History seemed to limit their peacebuilding agency, other teachers within government and ethnic 
systems were aware of the potential of History to contribute to peacebuilding, but were constrained by existing curricula frameworks. Similarly, in both Pakistan and Uganda issues of who gets represented in History, whose heroes and heroines get mentioned, how conflictual relationships with other countries are represented (e.g. India in Pakistani texts) are central to the discussion.

An interesting debate emerges across all the case studies on the differences in and emphasis between how the curriculum and textbooks deal with peacebuilding and social cohesion. One approach emphasises the generic inter-personal domain, focusing more on learning to live together, citizenship and values, rather than addressing difficult subjects and themes pertaining to justice more directly. In the case of Uganda, this is evident in the imprint of UNESCO's work, with the NCDC expressing a core set of values such as: the importance of serving societal needs, supporting literacy, numeracy and skills transferable to economic life, building national unity while reflecting diversity etc. In contrast in South Africa, there is coverage of difficult issues: depression, suicide, rape, HIV, gun crime, and gangs etc. However, as noted in the review, there is a sense that social cohesion and peacebuilding subjects such as 'Life Orientation' are often seen as easy, non-essential subjects, and often get crowded out with an ever-expanding curriculum.

Similarly, a discussion over the timing of different types of interventions in the school cycle is evident. More generic inter-personal content and topics are dealt with earlier and more difficult issues raised later in secondary education. However, as the authors of the Uganda report query, in a country where a majority of young people presently do not advance through secondary education can educators afford to leave the treatment of difficult national questions to the secondary curriculum?

Central to the debate on peacebuilding and social cohesion curriculum reforms in all the countries are issues of process (who is involved in the development of reforms), content (what is included and where), timing (when it is taught) and implementation (how it is taught). There are clear challenges in all domains. Curriculum reform, quite rightly, is a highly sensitive issue, particularly in relation to social cohesion and peacebuilding, and requires political sensitivity. As a result, agencies like UNICEF and UNESCO appear to favour implicit but quite generic - 'learning to live together' - approaches inherited from global 'peace education' models. The danger with these types of models is they tend to avoid local contextualised issues of conflict, ethnicity, and class relations that often constitute the real drivers of conflict. The danger inherent in this approach is that it avoids debating local issues of social injustice, redistribution, recognition and representation and may inadvertently contribute to reinforcing these inequalities through a 'pacifying' rather than transformatory approach, favouring forgiveness over justice and acceptance over social transformation. While dealing directly with key issues of racism, injustice, ethnic divisions, and conflict histories is difficult and requires teachers with strong skills, it has the potential to promote much more grounded and locally relevant knowledge that might contribute to transformatory outcomes. 


\section{CONCLUSIONS ON TEACHERS, PEACEBUILDING AND SOCIAL COHESION}

In this final conclusion we try to distill some messages from the research evidence. First, a fair deal for teachers in terms of pay, conditions of service and status is foundational: poorly paid, demoralised and over-worked teachers are unlikely to become change agents. Second, context is important to render a historicised and realistic account of inequality and its relationship to peace and reconciliation, therefore teacher interventions need to be developed from local and national contexts, not imported and adapted. In different contexts the balance between building national unity and promoting and protecting difference requires conflict-sensitive and contextually-based thinking to avoid unintended outcomes. Similarly, promoting generic rights and values is less likely to be transformatory than if peacebuilding issues are tailored to the particularities of the historical and political context and lived realities of teachers and students. Third, building social cohesion and peacebuilding through teachers requires a focus both on the teachers and the teaching - building reflexive practitioners aware of the conflict contexts they inhabit and able to articulate their own prejudices and develop clear positions is a pre-requisite for transmitting those processes on to students. Fourth, promoting peacebuilding and social cohesion is far more than a psycho-social and inter-personal process, and requires interventions across the redistribution, recognition, representation and reconciliation domains: measures for equitable and targeted funding, participation and inclusion are just as important as inter-group contact. Furthermore, compromises are inevitably necessary between redressing the drivers of conflict (often varying degrees of inequality in relation to redistribution, recognition and representation) and working on the legacies of conflict (reconciliation and bringing communities together). The latter requires compromise, which the former can often inflame. Fifth, contextualised peacebuilding and social cohesion objectives in teacher education and in the school curriculum writ large, need to be taken much more seriously, alongside efficiency and human capital priorities: peace and economic development are inseparable and shouldn't be traded off between themselves; a socially cohesive society provides the foundation for economic growth and prosperity and vice-versa. Political will on the part of national and international actors is therefore crucial.

Beyond the empirical findings, the study has also allowed us to test out the veracity of the 4 Rs peace and social justice framework. While its strength lies in its capacity to explore multiple dimensions of injustice: economic, political, cultural and historical, more work needs to be done to highlight the intersections between the different dimensions and the way that they often compound each other. There is a danger in the $4 \mathrm{R}$ approach towards segmentation, which can obscure the complex inter-relationships between different forms of social injustice. Similarly, we have learnt from the research process that the $4 \mathrm{R}$ 's analytical strength comes not from the framework itself, but from the quality of the researchers and their knowledge of the context and history of 
the education and socio-economic and political system under investigation. The $4 \mathrm{R}$ 's framework is a useful heuristic device for identifying the issues, but understanding their complexity and inter-relationship is time-consuming and requires committed and skillful researchers. In this process, we found that national ownership of the research, led by local researchers, working in close collaboration with international researchers, produced the best results. Finally, we also learnt that more work needs to be done to draw out the tensions between redressing the drivers of conflict in education (redressing inequality) and dealing with the legacies of the conflict (bringing people together). While these are political issues, best left in the hands of policy makers, it is our role as researchers to highlight the nature of the policy choices to be made and their implications.

In conclusion, and in the spirit of optimism with which we wish to approach the research, we should also recognise that in all the case studies teachers represent a potent potential force for change: they are located in almost every village and hamlet, they are often the biggest component of the national civil service, have the greatest potential to alter and improve the life chances of students, are respected and literate members of civil society, and despite the often difficult conditions under which they labour, overwhelmingly retain a strong conviction and commitment to their work. The task of policy makers is to maximise this potential through well thought through, context sensitive, equitable support, management and training - a difficult, but necessary challenge.

\section{ACKNOWLEDGMENT}

We would like to thank the ESRC-DFID for a research grant for the project Engaging Teachers in Peacebuilding in Postconflict Contexts: Rwanda and South Africa (PI: Yusuf Sayed). However, the views expressed in this paper reflect that of the authors and not the funders.

\section{REFERENCES}

Barber, M. and M. Mourshed. 2007. How the world's best performing school systems come out on top. London: McKinsey \& Company.

Cederman, L.E., N.B. Wiedmann and K.S. Gleditsch. 2011. Horizontal inequalities and ethnonationalist civil war: A global comparison. American Political Science Review 105(3): 478-495.

Chisholm, L. 2009. An overview of research, policy and practice in teacher supply and demand 1994-2008. Teacher Education in South Africa Series. Cape Town: HSRC Press.

Collier, P. and A. Hoeffler. 2004. Greed and grievance in civil war. Oxford Economic Papers 56(4): 563-595.

Datzberger, S., A. McCully and A. Smith. 2015. Uganda country report: Education and peacebuilding in Uganda. Research Consortium on Education and Peacebuilding, UNICEF PBEA Programme. Ulster: University of Ulster. 
Durrani, N., L. Kadiwal, A. Halai, S.K. Rajput and M. Novelli. 2015. Education and peacebuilding in Pakistan. Research Consortium Education and Peacebuilding. Falmer: University of Sussex and Aga Khan University.

FHI 360. 2015. Does horizontal education inequality lead to violent conflict? A global analysis. Washington DC: FHI 360 Education Policy and Data Center.

Fraser, N. 1995. From redistribution to recognition? Dilemmas of justice in a 'post-socialist' age. New Left Review 1(212): 68-93.

Fraser, N. 2005. Reframing justice in a globalized world. New Left Review 36: 79-88.

Galtung, J. 1976. Peace, war and defence: Essays in peace research. Vol. 2. Copenhagen: Ejlers.

HEC. 2010. Curriculum of education. B.Ed. 4-year Degree Programme (elementary, secondary), Associate Degree in Education, MS/M.Ed. Education-revised 2010. Islamabad: Higher Education Commission. Retrieved from http://www.hec.gov.pk/InsideHEC/Divisions/AECA/ CurriculumRevision/Documents/Education-2010.pdf (accessed 14 May 2016).

Higgins, S., E. Maber, M.T.A. Lopes Cardozo and R. Shah. 2015. Education and peacebuilding in Myanmar. Summary Report. Research Consortium Education and Peacebuilding, University of Amsterdam.

Lederach, J.P. 1995. Preparing for peace: Conflict transformation across cultures. Syracuse: Syracuse University Press.

Lederach, J.P. 1997. Building peace: Sustainable reconciliation in divided societies. Washington DC: United States Institute of Peace Press.

Metro, R. 2015. Students and teachers as agents of democratization and national reconciliation in Burma. In Metamorphosis: Studies in social and political change in Myanmar. Edited by R. Egreteau and F. Robinne. Singapore: NUS Press.

Naylor, R. and Y. Sayed. 2014. Teacher quality: Evidence review. Office of Development Effectiveness: Commonwealth of Australia.

Novelli, M. 2016. Capital, inequality and education in conflict-affected contexts. British Journal of the Sociology of Education 37(6): 848-860.

Novelli, M. and A. Smith. 2011. The role of education in peacebuilding: A synthesis report of findings from Lebanon, Nepal and Sierra Leone [Research Study]. UNICEF. Retrieved from: http:// www.unicef.org/evaldatabase/index_61271.html (accessed 11 October 2016).

Novelli, M., M. Lopes Cardozo and A. Smith. 2015. A theoretical framework for analysing the contribution of education to sustainable peacebuilding: 4Rs in conflict-affected contexts. Retrieved from: http://learningforpeace.unicef.org/wp-content/uploads/2015/05/TheoreticalFramework-Jan15.pdf (accessed 16 June 2016).

Piketty, T. 2014. Capital in the 21st century. Cambridge, MA: Harvard University Press.

Sayed, Y., A. Badroodien, Z. McDonald, L. Balie, T. De Kock, C. Garisch and K. Foulds. 2015. Teachers and youth as agents of social cohesion in South Africa. Research Consortium Education and Peacebuilding. Cape Peninsula University of Technology and University of Sussex.

Sinclair, M. 2002. Planning education in and after emergencies. Paris: UNESCO, International Institute for Educational Planning.

Stewart, F. 2010. Horizontal inequalities as a cause of conflict: A review of CRISE findings. A Background Paper. World Development Report, 2011. Retrieved from: http://siteresources. 
worldbank.org/EXTWDR2011/Resources/6406082-1283882418764/WDR_Background Paper_Stewart.pdf (accessed 27 October 2016).

UCRNN. 2014. Implementation of the convention on the rights of the child in Uganda. Kampala: UCRNN.

UNESCO-IIEP. 2006. Guidebook for planning education in emergencies and reconstruction, 12-25. UNESCO, International Institute for Educational Planning.

World Bank. 2012. Can low cost-private schools improve learning? Washington DC: Human Development Network, The Wold Bank. 